\title{
PENERAPAN IDEOLOGI KOMUNIS OLEH XI JINPING SEBAGAI BENTUK INDOKTRINASI TERHADAP MASYARAKAT TIONGKOK MELALUIMODEL ALTHUSSERIAN
}

\author{
Muhammad Habib Pashya', Nurul Faqiriah', Nani Septianie', Gufron \\ Gozali ${ }^{1}$, Elys Krisdiana ${ }^{1}$, dan Yeta Purnama ${ }^{1}$ \\ ${ }^{1}$ Program Studi Hubungan Internasional, Universitas Islam Indonesia
}

\begin{abstract}
ABSTRAK
Latar Belakang: Setelah mengalahkan kapitalisme di era Chiang Kai-Shek, Mao Zedong mengambil Tiongkok daratan dengan menerapkan ideologi komunis. Ideologi tersebut sangat kuat dan terikat dengan masyarakat yang ada di Tiongkok. Revolusi budaya Mao pada tahun 1960an, menjadi fakta nyata adanya mulainya proses doktrin komunis melalui buku merah.

Tujuan: Penelitian ini bertujuan untuk menganalisis dan mengkaji peran model althusserian sebagai bentuk proses doktrin ideologi komunis kepada masyarakat Tiongkok di era Xi Jinping

Metode: Adapun untuk mendukung penelitian ini akan menggunakan metode kualitatif dengan mengedepankan data sekunder seperti dari buku, jurnal, artikel, hingga lapor an yang sudah kredibilitas.

Hasil: Kebijakan Mao dilanjutkan hingga generasi kelima yaitu Xi Jinping. Berbeda dengan Mao Zedong, Xi mencoba untuk memanfaatkan era digital untuk menyebarkan ide komunis. Maka daripada itu, konsep yang sudah berada di era Mao sudah diperbarui oleh Xi untuk mengatur masyarakat sehingga tidak terpengaruhi oleh pihak Barat. Melalui media, Xi mencoba untuk menerapkan beberapa kebijakan dengan mengontrol langsung media untuk pro terhadap PKC. Misalnya, Xinhua.net dan CGTN. Dari aspek agama, Xi menggunakan prinsip sinisasi agama. Terakhir, Xi juga menggunakan aspek pendidikan sebagai bentuk proses doktrin. Menurutnya, komunisme seharusnya sudah ada di dalam sektor pendidikan untuk nantinya dapat berkembang ke masyarakat. Pada intinya, sebagai titik kulminasi, Xi menginginkan adanya sikap patriotisme dan nasionalisme dari masyarakatnya kepada negara dan PKC.

Kesimpulan: Model althusserian sudah selaras dengan kebijakan pemerintah Tiongkok dalam mengontrol masyarakatnya. Di era $\mathrm{Xi}$, perkembangan dalam indoktrinasi masyarakat berkembang melalui media, agama, dan pendidikan.
\end{abstract}

Kata Kunci: Xi Jinping, Masyarakat Tiongkok, Komunis, Model Althusserian.

\begin{abstract}
Background: After defeating capitalism in the Chiang Kai-Shek era, Mao Zedong took mainland China by implementing communist ideology. This ideology is very strong and tied to the society in China. Mao's cultural revolution in the 1960s became a clear fact of the beginning of the process of communist doctrine through the red book.

Objectives: This study aims to analyze and examine the role of the althusserian model as a form of communist ideological doctrinal process to Chinese society in the Xi Jinping era.

Methods: To support this research, qualitative methods will be used by prioritizing secondary data such as books, journals, articles, and reports. which has credibility.
\end{abstract}

Result: Mao's policies were continued to the fifth generation, namely Xi Jinping. In contrast to Mao Zedong, Xi tried to take advantage of the digital age to spread communist 
ideas. Therefore, the concept that already existed in Mao's era has been updated by Xi to regulate society so that it is not influenced by the West. Through the media, Xi tried to implement some policies by directly controlling the media in favor of the CCP. For example, Xinhua.news and CGTN.From the religious aspect, Xi uses the principle of religious sinization. Finally, Xi also uses the educational aspect as a form of the doctrinal process. According to him, communism should already exist in the education sector so that later it can develop into society. In essence, as a culmination point, Xi wants an attitude of patriotism and nationalism from his people towards the state and the CCP.

Conclusion: The model althusserian is in line with the Chinese government's policy of controlling its people. In the Xi era, developments in people's indoctrination progressed through the media, religion, and education.

\section{Keywords: Xi Jinping, Chinese Society, Communist, Althusserian Model}

\section{PENDAHULUAN}

Tiongkok adalah negara kuno. Sejak dikenal sebagai Republik Rakyat Tiongkok, Tiongkok berbentuk dinastidinasti besar yang pernah menjelajahi dunia seperti Zhou, Qin, Qing, Song, dst. Dibalik beragamnya dinastitersebut, Tiongkok juga melahirkan pemikirpemikir dunia terbaik seperti Confucius. Disamping itu, Tiongkok juga dihadirkan oleh masa-masa berat seperti kolonialisasi. Jepang, Manchu, dan Britania menjadi tiga penjajah besar yang ada di Tiongkok. Abad 20, menjadi ujian bagi Tiongkok untuk berhadapan dengan penjajah tersebut seperti adanya Perang Jepang- Tiongkok hingga Perang Candu 1 dan 21 . Namun, penjajahan tersebut tidak menuntut Tiongkok mengalami pergeseran dalam budaya. Terbukti, walaupun sudah dijajah British, Tiongkok tidak pernah menjadikan bahasa Inggris sebagai salah satu bahasa nasional. Bahkan, budaya Tiongkok seperti bahasa diadopsi oleh Kaisar Jepang dan di lokalisasi di negaranya.

Dari tahun 1927, Tiongkok sudah mulai memiliki gejolak perang. Setelah runtuhnya, dinasti Manchu, Tiongkok mendirikan bentuk negara Republik dengan dipimpin oleh partai Kuomintang ${ }^{7}$. Namun, sistem kapitalis yang dijalankan oleh Kuomintang tidak sejalan dengan Partai Komunis China atau PKC. Perang Sipil pecah pada tahun 1949 dan diakhiri oleh kemenangan Mao Zedong dari Partai Komunis China (PKC). Dibawah kekuasaan Mao, Tiongkok mengubah sistemnya dengan drastis seperti adanya Great Leap Forward ${ }^{2}$. Ditambah lagi, ambisi Mao yang ingin meningkatkan nasionalisme para rakyatnya yang dibawah ide komunisme dengan mengeluarkan kebijakan Cultural Revolution pada tahun 1960$\mathrm{an}^{3}$. Salah satu hasil maupun bukti yang tertuju dari kebijakan tersebut adalah buku merah. Hal itu juga membuktikan pada saat itu Mao tidak menyukai adanya unsur kapitalisme dan imperialisme. Maka daripada itu, Mao selalu hadir dengan gagasannya yang berupa sosialisme dan komunisme.

Kebijakan revolusi budaya Mao semakin kuat pada tahun 1975. Pada saat itu terjadi adanya pembantaian terhadap Muslim Hui di Shadian, Tiongkok 4 . Para Muslim tersebut dipaksa untuk menganut ide-ide komunis dan bergabung dengan etnis asli Tiongkok, etnis Han. Sehingga, salah satu contoh tersebut membuat etnis Tiongkok mengalami heterogen namun etnis Han masih menjadi mayoritas. Berdasarkan laporan dari Sixth National Population Census of the People's Republic of China, hingga 2021, Tiongkok memiliki 56 etnis grup 5 . Namun, etnis-etnis tersebut tidak memiliki jumlah yang proporsional atau memiliki gap presentasi yang jauh.

Terbukti, sebanyak 92\% etnisetnis tersebut dikuasai etnis $\mathrm{Han}^{6}$. Perkembangan tersebut selaludijadikan tombak utama bagi pemerintah Tiongkok untuk mengatur para etnisnya. Pengaturan etnis yang terimplementasi kepada masyarakat tersebut berkembang di era Xi Jinping.Presiden $\mathrm{Xi}$, menginginkan Tiongkok berjaya layaknya di era dinasti dan nasionalis 
seperti di era Mao. Maka dari itu, Xi tidak hanya mengeluarkan proyek ambisius bernama Belt and Road Initiative namun memiliki program besar untuk membuat rakyatnya tetap patuh terhadap ide komunisme. Komunisme dan sosialisme berjalan satu alur dengan Marxisme yang dulu dikemukakan olehKarl Marx pada abad19.

Namun, hal ini dikembangkan oleh Louis Althusser yang merupakan filsuf Perancis yang populer pada tahun 1960an-1970an. Ide ideologis dari Althusser sering disebut dengan model althusserian. Model tersebut sejalan dengan kebijakan yang dikeluarkan Xi Jinping terhadap etnis maupun masyarakatnya terkait dengan komunisme. Sudah ada penelitian yang membahas model Althuserian dalam sosial-budaya Tiongkok seperti Nivision pada 1956, Knight pada 2009 dan Yan pada Tahun 2018. Namun, studi sebelumnya belum membahas mengenai kebijakan Xi Jinping dalam mengatur masyarakat Tiongkok dari aspek sosial-budaya melalui ideologi komunisme berdasarkan model althusserian. Maka daripada itu, penelitian ini akan berfokus pada hal tersebut untuk menyempurnakan penelitian sebelumnya.

\section{METODE PENELITIAN}

Penerapan model althusserian di Tiongkok dalam penelitian ini akan didukung oleh metode kualitatif. Secara definisi, menurut Creswell, "Penelitian kualitatif adalah proses penyelidikan pemahaman berdasarkan tradisi metodologis yang berbeda dari penyelidikan yang mengeksplorasi masalah sosial atau manusia. Peneliti membangun gambaran yangkompleks, holistik, menganalisis kata- kata, melaporkan pandangan rinci informasi, dan melakukan studi dalam pengaturan alami"8.

Definisi dari Crewell diperkuat dari penelitian sebelumnya oleh Profesor Wai Fong Chua. Chua mengatakan bahwa metode kuantitatif sebenarnya menekankan pada hipotesis-deduktifmemiliki keterbatasan dalam menjangkaupermasalahan yang diteliti ${ }^{9}$. Maka daripada itu, penelitian ini akan cenderung menggunakan sumber sekunder seperti buku, jurnal, artikel, bahkan laporan-laporan yang tervalidasi dan sudah kredibilitas.

Sumber-sumber sekunder yang digunakan juga berhubungan dengan judul penelitian yang dijadikan pembahasan. Namun spesifikasinya, buku yang digunakan akanbertemakan keadaan Tiongkok atau pemerintah Tiongkok. Disamping itu, penelitian ini juga akan mengambil laporan-laporan yang sudahdisediakan oleh pemerintah Tiongkok yang nantinya berkaitan dengan data sensus atau demografi. Pada penelitian ini, akan berfokus kepada pemerintah Tiongkok sebagai subjek dan masyarakat Tiongkok sebagai objek. Kedua bagian tersebut tentu akan berpengaruh kepada penerapan model teori yang akan digunakan.

\section{HASIL PENELITIAN}

Setelah melakukan penelitian, ideologi menjadi salah satu penerapan yang penting di Tiongkok. Ideologi berfungsi sebagai ide-ide penuntun yang digunakan sebagai melegalkan kebijakan dan legitimasi kekuatan. Salah satu cara yang digunakan untuk menyebarkan ideologi tersebut dengan cara institusi-institusi maupun kelompok-kelompok yang ditugaskan oleh negara. Dari era Mao hingga Hu Jintao, sudah menggunakan elemenelemen tersebut seperti pendidikan, agama, dan media atau pers.

Penerapan ideologi tersebut berkorelasi dengan model althusserian yang diperkenalkan oleh Filsuf Perancis, Louis Althusser untuk mengamati kebijakan domestik Tiongkok terkait dengan mengatur ide komunis masuk ke dalam ranah masyarakat. Dalam penelitian ini, penerapan model althusserian tidak hanya terjadi dari era Mao, namun berkembang hingga Xi Jinping.

Reformasi yang digunakan dari era Deng tentu diperketat oleh $\mathrm{Xi}$. Presiden Tiongkok, Xi Jinping mencoba untuk memanfaatkanakselerasi internet dan keambisiusannya untuk memperkuat posisinya sekaligus 
pemikiran komunis kepada masyarakatnya. Melalui media, Xi mencoba menerapkan era digital (walaupun ada censorship) untuk menyebarkan pengaruhnya kepada masyarakat. Dari aspek agama, Xi menggunakan prinsip sinisasi agama yang dulu telah digunakan juga dengan nama sinisasi marxisme. Terakhir, Xi juga menggunakan aspek pendidikan sebagai bentuk proses doktrin. Menurutnya, komunisme seharusnya sudah ada di dalam sektor pendidikan untuk nantinya dapat berkembang ke masyarakat. Pada intinya, sebagai titik kulminasi, Xi menginginkan adanya sikap patriotisme dan nasionalisme dari masyarakatnya kepada negara dan PKC.

\section{PEMBAHASAN \\ 4.1. Korelasi Model Althusserian dan Ide Komunis Tiongkok}

Perkembangan komunisTiongkok berawal dari studi marxisme di Universitas Nasional Beijing oleh Mao Zedong.Kelompok studi ini berkembang menjadi Partai Komunis China (PKC) pada 1 Juli 19217. Seiring perkembangannya, PKC bekerjasama dengan Kuomintang (KMT) dan tergabung dalam satu aliansi bersama untuk memperluas pengaruh kekuasaan. Dilain hal, PKC juga bersekutu dengan Kuomintang untuk menentang penguasaan militer (Pemerintahan Beiyang). Pemerintahan Beiyang menguasai berbagai wilayah di Tiongkok $^{10}$. KMT dan PKC bertujuan untuk menumpas semua agar kekuasaan bisa beralih kepada sipil. Namun dalam perkembangannya, KMT dan PKC adalah dua partai yang memiliki ideologi politik yang berbeda. KMT lebih cenderung ke arah yang kapitalis dan PKC lebih condong kearah sosialis atas ajaran dari Mao. Atas perbedaan tersebut, pada 1934, PKC melakukan perjalanan panjang menuju wilayah Yan'an yang dikenal dengan peristiwa long march ${ }^{11}$. Long march membawa Mao menjadi pemimpin Partai Komunis China (PKC) dan sebagairevolusi terbesar pada abad ke20. Sehingga, Mao berperan banyak dalam merancang strategi perang gerilya. Mao menjadikan petani yang menduduki jumlah terbesar dari rakyat China sebagai kekuatan pokok revolusi. Keberhasilan Partai Komunis China (PKC) sebagai partai yang melahirkan Republik Rakyat China (RRC) dan mengalahkan KMT tidak terlepas dari gagasan perang gerilya Mao, yaitu "Desa Mengepung Kota". Gagasan ini merupakan prinsip militer untuk memenangkan medan perang yang dilakukan oleh kekuatan lemah melawan kekuatanyang lebih kuat. Mao mulai mengenal Revolusi Bolshevik dan komunisme di Rusia, sehingga menjadi aktif menulis jurnal. Artikel yang menjadi sorotan nasional adalah "The Great Union of the Popular Masses"12. Isinya mengajak golongan petani, buruh, pelajar, kaum perempuan, guru, dan polisi, untuk bersatu menggulingkan penindasan kaum kapitalis. Dengan berhasil mendepak kapitalis ke Taiwan, Mao mengambil ahli kekuasaan Tiongkok dengan memerdekakan diri pada tahun 1949. Sehingga, perkara ideologi Mao yang sudah hadir dari gerakan dan keresahan terhadap kapitalis, terimplementasi kepada ideologi yang diterapkan ke Tiongkok yaitu komunisme.

Salah satu ciri khas Tiongkok adalah pengaturan ketat masyarakat yang dilakukan pemerintah. Hal ini tentu selaras dengan konsep yang dikemukakan oleh filsuf Perancis, Louis Pierre Althusser. Althusser adalah seorang Marxisme yang sangat kritis terhadap aspekstrukturalisme, sehingga dikenal sebagai ahli teori ideologi. Sebagai ahli, Althusser pernah menjadi anggota Partai Komunis Perancis pada tahun 1948. Darisana, gagasan terbesar yang dimilikinya adalah membentuk dialektika (komunikasi dua arah) yang saling berkaitan satu dengan yang lain. Disamping itu, Althusser juga mencoba untuk membaca dan memahami kembali gagasan- gagasan Karl Marx. Refleksi dari perjuangan Marx, di dalam ideologi manusia menjadi sadar akan pertentangan kelas dan berjuang untuk menghapusnya. Maka daripada itu menurut Althusser, ideologi adalah segala sesuatu yang sudah tertanam dalam diri manusia sepanjang hidupnya 
dan menempatkan manusia di bawah pengaruh sosial. Melalui pandangannya, ideologi adalah suatu hubungan langsung antara manusia dengan dunia, sementara 'cara produksi kapitalis' menjadi cara agar eksploitasi dipertahankan, dan setiap individu adalah subjek dalam kapitalisme.

Maka Althusser menyatakan bahwa, ideologi menjadi pedoman utama yang dapat mengendalikan politik, melalui kontrol terhadap sekolah, agama, dan pers (media). Konsep yang diargumenkan oleh Althusser sering disebut dengan model althusserian. Model tersebut menjadi pernyataan yang kuat didalam bermasyarakat yang dilakukan oleh pemerintah Tiongkok sejak berdirinya Partai Komunis China atau PKC. Disamping itu, ideologi dianggap sebagai ide-ide yang digunakan untuk kepentingan dan legitimasi kebijakan.

\subsection{Kontrol terhadap Masyarakat \\ Sebelum Era Xi Jinping}

Setelah merdeka, Mao tidak hanya membuat kebijakan 'Gerakan Seratus Bunga' dan'Gerakan Lompatan JauhKedepan', namun juga melakukan revolusi kebudayaan pada tahun 19661976. Revolusi tersebut dimaksudkan untuk menghidupkan kembali revolusi komunis dengan cara memperkuat doktrin ideologi komunis di Tiongkok ${ }^{13}$. Dalam pertemuan Komite Sentral ke-8 yang digelar pada tahun 1966 telah tertulis 16 poin resolusi yang menjadi petunjuk implementasi dari revolusi kebudayaan yangbeberapa diantaranya yakni penghapusan empat hal kuno yang meliputi kebudayaan, gagasan pemikiran, tradisi, serta kebiasaan kuno yang tertuang dalam slogan "Smash the four olds"14. Penguatandoktrin ideologi komunis yang dilakukan Mao Zedong melalui revolusi kebudayaan dilatarbelakangi oleh banyaknya pejabat Tiongkok yang mulai meninggalkan paham komunis ${ }^{15}$.

$$
\text { Dua minggu setelah }
$$

dikeluarkannya kebijakan revolusi budaya, tepatnya pada tanggal 1 Juni media cetak yang dimiliki oleh PKC menyerukan massa untuk terlibat dalam revolusi budaya ${ }^{13}$. Dalam melakukan revolusi kebudayaan Mao Zedong menggerakan massa mulai dari masyarakat, petani hingga mahasiswa melalui red guard. Bahkan mahasiswa seluruh kampus di Tiongkok juga membentuk red guard division untuk mendukung revolusi kebudayaan, namun pada 1966 sempat terjadi ketegangan antara red guard dengan pasukan Mao Zedong akibat desakan terhadap red guard untuk menghancurkan four olds ${ }^{13}$. Terlepas daripada itu, pada 1968 Mao juga mengirimkan jutaan anak muda untuk dikirim ke desa dan dididik ulang oleh petani untuk mengenal konsep-konsep sosialis $^{16}$.

Slogan "Smash the four olds" diwujudkan dengan pelarangan penggunaan pakaian lama, festival kebudayaan, normadalam masyarakat, selanjutnya penghancuran buku, benda bersejarah dan penghancuran rumah ibadah tanpa terkecuali. Hal ini dibuktikan dengan penghancuran kuil Buddha serta gereja Katolik Roma yang dilakukan di kota Shanghai, Peking, Canton dan Hancow selama masa revolusi kebudayaan. Mao juga membuat kebijakan ketat untuk mengatur kehidupan beragama masyarakat Tiongkok. Para pemeluk Buddha, Tao, dan Islam wajib mengikuti kelas patriotik komunis ${ }^{17}$.

Tidak hanya slogan smash the four souls, Mao juga menggunakan buku sebagai media propagandanya. Pada masa revolusi kebudayaan Mao mewajibkan setiap masyarakat Tiongkok tanpa terkecuali memiliki buku merah sebagai bukti ketaatanterhadap otoritas yang ada. Buku merah berisi kutipan, ide, pidato serta puisi oleh Mao untuk dijadikan pedoman kehidupan masyarakatTiongkok ${ }^{18}$. Untuk menekan kelompok oposisi, Mao juga memobilisasi para pelajar yakni mahasiswa dan murid sekolah menengah atas dengan memberikan perintah untuk menyiksa para guru dan cendikiawan, Mao menganggapbahwa semakin banyaknya para kaum terpelajar maka semakin besar peluang untuk melakukan perlawanan kepada pemerintah, dan melabeli mereka sebagai "Stinking number nine" atau dapat dimaknai sebagai kelompok yang terlarang. Upaya untukmenghilangkan pengetahuan eksternal bukan hanya 
dilakukan oleh zaman Mao, namun juga pernah berkaca kebijakan yang dilakukan oleh kaisar Qin Shi Huangdi yang merupakan kaisar pertama Tiongkok ${ }^{19}$.

Terkait dengan aspek pendidikan, Mao melakukan perubahan terhadap sistempendidikan yang lebih ke arah sosialis $^{20}$. Reformasi sistempendidikan dapat dilihat ketika Administrative Council of the Central People's Government resmi menetapkan sistem akademik Tiongkok pada 1 Oktober 1951 yang mengubah sistem universitas yang semula mengadopsi model Inggris dan Amerika menjadi model Soviet ${ }^{21}$. Meskipun di masa awal terjadinya revolusi budaya sekolah dan universitas sempat ditutup akan tetapi pada awal 1970-an universitas dan perguruan tinggi kembali dibuka namun tidak untuk masyarakat umum tetapi hanya untuk petani, tentara dan juga politisi ${ }^{16}$. Di era Deng. mulai menghidupkan kembali atau mereformasi sosial. Salah satunya melalui institusi akademik. Dalam National conference of education pada 22 April 1978 Deng Xiaoping mengatakan, "Sekolah menjaditempat pelatihan personil yang kompeten untuk konstruksi sosialis"23. Oleh karena itu sejak 1978 Deng Xiaoping aktif mengirimkan mahasiswa Tiongkok untuk belajar keluar negeri. Semua kebijakan ini mengakibatkan lahirnya sentralitas kebudayaan dalam masyarakat Tiongkok, ini dibuktikan dengan hanya diperbolehkannya penggunaan bahasa mandarin dalam komunikasi sehari-hari, pengetatanarus informasi dalam masyarakat dan lain sebagainnya. Pada akhirnya ini menjadi pintu pembuka bagi penguatan penanaman ideologi dalam masyarakat Tiongkok.

Reformasi sosial di era Deng berdampak kepada era selanjutnya. Misalnya, diskusi menyangkut agama juga kembali dihidupkan bahkan sampai dituangkan ke dalam penelitian dalam bentuk jurnal. Meskipun di era Deng Xiaoping Tiongkok sudahmulai terbuka bukan berarti masyarakat sudah bebas, masyarakat Tiongkok tetap diharuskan untuk mematuhi nilai- nilai sosialis seperti yang tertuang dalam pembukaan konstitusi Tiongkok "Seluruh bangsa
China akan terus mematuhi kediktatoran demokratik rakyat dan jalan sosialis, bertahan dalam reformasi dan keterbukaan terhadap dunia luar"24. Hal ini dibuktikan dengan pergerakan kelompok beragama selalu dikontrol oleh biro urusan agama yang bekerja sesuai denganarahan partai ${ }^{25}$. bahkan, pada 1997 Tiongkok mengeluarkan undang- undang mengenai kejahatan di dunia maya, Undang-undang ini bertujuan untuk mengontrol informasi sensitif yang dianggap mengancam Tiongkok, tidak hanya melalui undang-undang upaya pemerintah Tiongkok dalam mengontrol media juga dapat dilihat Golden Shield Project yang resmi beroperasi pada $2006^{18}$. Proyek Golden Shield ini telah mempekerjakan puluhan ribu orang untuk mengawasi internet di Tiongkok (ibid). Bahkan, semangat untuk menanamkan nilai sosialisme dalam kehidupan masyarakat juga dapat dilihat ketika $\mathrm{Hu}$ Jintao dalam pertemuan PKC ke-17 pada oktober 2007 menekankan bahwasanya penerapan nilaisosialisme tidak untuk partai tetapi juga untuk diterapkan di keseharian masyarakat ${ }^{26}$.

\subsection{Model Althusserian di Era Xi Jinping}

Setelah indoktrinasi yang masif sudah terjadi di era Mao hingga $\mathrm{Hu}$ Jintao, perkembangan kebijakan tersebut berjalan di era XiJinping. Untuk melihat proses doktrin tersebut, model althusserian akan berjalan melalui tiga cara yaitu sekolah, pers, dan agama. Berdasarkan data dari Reporters Without Borders, Tiongkok merupakan negara dengan peringkat 177 dari 180 negara terkait dengan kebebasan persnya. Dari data tersebut dapat disimpulkan bahwa media-media di Tiongkok belum sepenuhnya menjamin warga negaranya untuk memiliki hak kebebasan dalam menggunakan media. Menurut Central Intelligence Agency (CIA) menyebutkan bahwa pemerintah Tiongkok akan mengambil kendali terkait penggunaan media dan opini publik. Data Freedom House Report pada tahun 2018 mengatakan bahwa rezim otoriter Tiongkok akan menjadi semakin represif dalam beberapa tahun terakhir dalam hal mengontrol 
penggunaan media kepada kelompok masyarakat.

Presiden Xi Jinping menegaskan bahwa media dapat menjadi peran yang sangat pentinguntuk mempertahankan reputasi sebuah negara. Pada National Propaganda and Ideology Work Conference 2013, Xi Jinping mengatakan bahwa, "Tiongkok harus berusaha untuk memajukan kapasitas komunikasi internasional, berinovasi metode propaganda asing, memperkuat konstruksi sistem percakapan, berusaha untuk memalsukan konsep baru, kategori baru dan ungkapan baru yang beredar antara Tiongkok dan dunia luar, dengan menceritakan kisah Tiongkok dengan baik, dan memperkuat kekuatan wacana (China) secara internasional". Selain itu, melalui media Tiongkok dapat menjadikan strategi ii untuk mewujudkan "China's Dream" dalam mewujudkan semua kebijakankebijakan yang diinisiasi oleh Presiden Xi yang telah diluncurkan di semua platform media pemerintah, termasuk televisi, surat kabar, radio, papan reklame dan poster. "Kita perlu dengan penuh semangat mendorong dan mempromosikan nilai-nilai inti sosialis segera membangun sistem nilai yang sepenuhnya mencerminkankarakteristik Tiongkok, identitas nasional kita" Ungkap Presiden Xi.

Beberapa media yang aktif dan berada dibawah naungan PKC berupa melalui saluran televisi, radio, hingga surat kabar sebagai strategi untuk mengontrol masyarakat. Xinhua News Agency, China Global Television Network (CGTN), The International Arm of State Broadcaster CCTV, bahkan saluran radio China (China Radio International), dan surat kabar-surat kabar lainnya seperti The China Daily Newspaper hingga the People's Daily newspaper merupakan sebuah media tiongkok yang mana media tersebut dikendali secara penuh di bawah Partai Komunis China dalam memengaruhi arus informasi global melalui propaganda, sensor, pengawasan, dan kontrol. Terlebih di masa pandemi Covid-19 media Tiongkok memainkan peran yang sangat krusial dalam mengontrol dan membatasi isu-isu yang berkaitan dengan kebijakan domestiknya. Dilansir dari BBC melaporkan bahwa terdapat 1.200 akun media sosial yang dibajak dikarenakan telah memberikan pesan negatif terhadap pemberian kritik terkait penanganan China dalam mengatasi wabah virus corona ${ }^{27}$.

Dengan adanya fenomena ini menunjukan bahwa kontrol Pemerintah Tiongkok melalui Partai Komunis China sangat memiliki keterlibatan penuh dalam pengontrolan media Tiongkok. Selain itu dalam pengontrolan media di era Presiden Xi dapatdibuktikan dengan adanya undang-undang yang diterapkan untuk menghukum seseorang apabilamenggunakan media sosial tidak sesuai aturan yang ditetapkan oleh Pemerintah Tiongkok. Peraturan tersebut terdapat dalam Amandemen IX Hukum PidanaRepublik Rakyat Tiongkok yangditetapkan pada tanggal 29 Agustus 2015 dan berlaku efektif mulai daritanggal 1 November 2015. Yang mana pada alenia pasal 219A disebutkan bahwa,"Barang siapa yang membuat informasi palsu tentang situasi risiko, penyakit epidemi, bencana atau keadaan darurat dan menyebarkan informasi tersebut di jaringan informasi ataumedia lain, atau dengan sengajamenyebarkan informasi palsu tersebut di jaringan informasi atau media lain, yang secara serius mengganggu ketertiban umum, dipidana dengan pidana penjarapaling lama tiga tahun, pidanakurungan atau pengawasan; dan jika mengakibatkan akibat yang serius, diancam dengan pidana penjara tidak kurang dari tiga tahun tetapi tidak lebih dari tujuh tahun"28.

Censorship Tiongkok memainkan peran yang sangat penting dalam mempengaruhi masyarakat melalui media untukmeredam suara-suara kritis secara global seperti mengambil langkahuntuk membatasi,

menghukumlaporan masuk yang dapat merusak reputasi Tiongkok. Partai KomunisChina menggunakan berbagai cara untuk dapat mempengaruhi domestik agar dapat meningkatkan kualitas medi China dengan menyediakan beberapa fasilitas,melalui 
propaganda terbuka, membuka pusat penelitian, pelatihan, dan investasi media.Investasi media yang meluas, penyebaran propaganda, dan pertukaran partai ke partai dengan mempromosikan model tata kelolanya secara signifikan telah mempengaruhi dunia internasional selama dua dekade terakhir ${ }^{29}$. Yang mana media China harus mencerminkan kebijakan partai, menjaga otoritas partai, dan menjaga persatuan partai. Dan Presiden Xi pada bulan Februari 2016 di media outlet China mengatakan bahwa,"tugas media China bukanlah untuk menginformasikan publik dan mencari kebenaran. Sebaliknya, itu untuk "melaporkan" cerita yang dapat menguntungkan $\mathrm{Xi}$ dan partai serta menyensor isu-isu yang tidak layak untuk dipublikasi yang dapat merusak reputasi China." 30 .

Di era Xi Jinping, censorship sangat didahulukan demi menjaga aroma komunisme agar tidak diikut campurkan dengan liberalisme milik Amerika Serikat. Jadi, pers tidak diperbolehkan untuk mengkritik PKC dalam hal apapun. Untuk itu, Xi juga pernah mengeluarkan kebijakan dalam memblokir media internasional lainnya seperti the New York Times, the Times of India, dan the Wall Street Journal. Lebih daripada itu, peninggalan Mao Zedong yang berupa 'buku merah' juga ada di eraXi. Bedanya, Xi memakai kemajuan teknologi dengan berbentuk aplikasi. Pada tahun 2019, aplikasi, "Study (Xi) Strong Country," mulai naik peringkat dan menjadi aplikasigratis yang paling banyak diunduh di App Store Tiongkok bahkan dapat melampaui beberapa aplikasibesar yang fenomenal sepert WeChat dan TikTok ${ }^{31}$. Dengan logo merah bertuliskan "belajar" dalam bahasa Mandarin, atau "belajar Xi" sebagai permainan kata yang cerdik, aplikasi ini bertujuan untuk membentuk pikiran bangsa dibawah kepresidenan Xi Jinping (lbid). Dengan aplikasi tersebut, Xi mengharapkan bahwa masyarakatnya yang cenderung aktif dalam internet (walaupun dibatasi) dapat meningkatkan patriotisme terhadap PKC dan kebijakan yang dibuatnya. Fakta tersebut terbukti berdasarkan studi yang dilakukan oleh Harvard Ash Center yang menyampaikan bahwa, rata-rata orang Tiongkok sangat mendukung kebijakan pemerintah daripada yang sebelumnya.

Cara Presiden $\mathrm{Xi}$ dalam melakukan proses indoktrinasi tidak hanya melalui media bukan sebagai instrumen tunggal namun juga melalui agama. Walaupun, dalam pasal No. 36 Konstitusi Tiongkok mengatakan bahwa,"warga negara Tiongkok memiliki kebebasan dalam kepercayaan keagamaan" tidak berarti bahwa pemeluk agamabebas dalam memeluk kepercayaan ${ }^{32}$. Di era Xi, masyarakat Tiongkok dipersilakan untuk bebas namun tidak meninggalkan ide komunisme. Dalam hal ini, Xi menginginkan adanya keabadian budaya yang harus dijaga secara sempurna oleh masyarakat Tiongkok. Hingga saat ini, ada lima agama yang diakui pemerintah Tiongkok seperti Taoisme, Buddha, Islam, Protestan,dan Katolik. Jika lima agama tersebut disatukan, berdasarkan laporan dari Freedom House, masyarakat Tiongkok terhitung sudah ada lebih dari 350 juta jiwa yang memiliki kepercayaan ${ }^{33}$.

Para pemilik kepercayaan tersebut dikontrol secara kuat oleh negara melalui the State Administration for Religious (SARA) and United Front Work Department (UFWD) ${ }^{34}$. Secara struktural, dua departemen tersebut dibantu secara administratif oleh lima asosiasi dibawahnya yang berupa the Buddhist Association of China (BAC), the Chinese Taoist Association (CTA), the Catholic Patriotic Association (CPA), the Protestant Three-Self Patriotic Movement (TSPM), dan the Islamic Association of China (IAC) ${ }^{35}$. Salahsatu fungsi yang paling penting dalam melihat lembaga tersebut adalah adanya kontrol terhadap umat beragama maupun kepalaagama untuk terdaftar di negara dan secara politis loyal terhadap Partai Komunis China. Ada beberapa contoh kontrol yang dibawah naungan PKC seperti tempat ibadah, pemimpin agama, konten yang teologis, dan festival tahunan yang agamis seperti haji atau ziarah (Ibid). 
Berdasarkan laporan dari The Sasakawa Peace Foundation tahun 2015, Xi sudah memperkenalkan frasa sinisasi agama di depan Konferensi dari the Central United Front Work. Xi berargumen bahwa,"urusan agama membawa kepentingan khusus dalam pekerjaan CPC dan pemerintah pusat [...] hubungan keamanan nasional dan penyatuan tanah air [...] teori agama sosialis dengan karakteristik Cina" 36 . Lebih daripada itu, sinisasi tersebut tidak hanya bermakna slogan untuk mengintegrasimasyarakat Tiongkok namun menjadi pedoman $X i$ Jinping untuk memperkuat tiga kunci kebijakan utama yaitu mempersingkat birokrasi yang ada di luar PKC untuk mengontrol ruang publik, menghidupkan kembali ideologi partai untuk seluruh aspek kehidupan di Tiongkok termasuk beragama, dan menghilangkan sikap maupun gerakan yang mengandung kontradiksi kepada ideologi Xi Jinping.

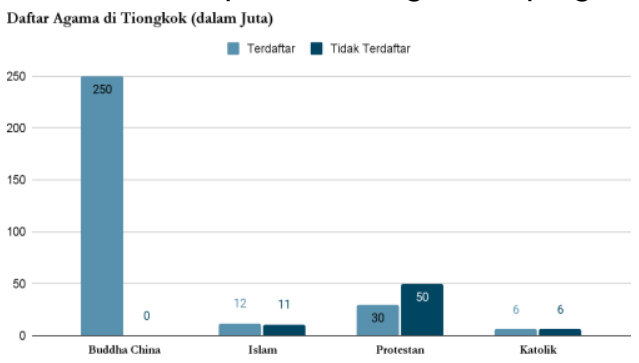

Grafik 1. Daftar Agama di Tiongkok ${ }^{33}$

Berdasarkan data tersebut memang menunjukan angka yang signifikan terhadap masyarakat yang tidak terdaftar dalam lembaga yang sudah disediakan oleh pemerintah Tiongkok seperti halnya Islam dan Kristen. Hal yang paling utama dalam penyebab tidak terdaftarnya agama tersebut adalah tidak ingin mengikuti peraturan yangsosialis dari pemerintah Tiongkok. Sehingga, kepercayaankepercayaan tersebut masih ingin mempertahankan identitas aslinya. Namun, kepercayaan yang tidak terdaftar tersebut dipaksa untuk taat pada peraturan dengan cara persekusi. Di era $\mathrm{Xi}$, persekusi tersebut cukup gencar dijalankan dengan tujuan untuk membentuk komunitas yang agamis dan kolektifdalam payung komunisme. Islam (Uighur) dan Kristen memiliki pertumbuhan yang cukup signifikan dalam beberapa tahun terakhir menjadi korban dari kebijakan tersebut. Kebijakan yang konsisten tersebut diperlakukan oleh Presiden Xi untuk mengintegrasi masyarakat. Sejauh ini, salah satu kepercayaan yang tidak terdaftar bahkan memberontak terhadap PKC adalahFalun Gong ${ }^{33}$.

Laporan dari BBC pada tahun 2021, sekitar 12 juta Uighur diXinjiang terpersekusi ${ }^{37}$. Sikap ini dipertegas terhadap keluarnya laporan yang sama dari Human Rights Watch, yang menjelaskan bahwa pemerintah Tiongkok sangat bertanggung jawab atas terjadinya persekusi budaya, kekerasan, hingga pemenjaraan secara massa ${ }^{38}$. Tidak hanya persekusi yang ada, masyarakat Uighur juga ditempatkan ke dalam kampkonsentrasi di daerah Xinjiang. Dilain hal, masyarakat Uighur juga dipaksa untuk kerja paksa seperti di sektor kapas. Namun, pemerintah Tiongkok selalu membantah pernyataan tersebut sebagai bagianyang nyata atau terjadi. Terkait dengan kamp konsentrasi bukan digunakan sebagai bagian dari kebijakan yang represif namun tempat pendidikan vokasi. Berdasarkan laporan yang dikeluarkan oleh pemerintah Tiongkok tahun 2014-2019, sudah ada 1,3 juta warga telah menjalani program tersebut. Program yang ditawarkan pemerintah Tiongkok berupa belajar bahasa Mandarin, menyanyikan lagulagu nasionalis, dan belajar propaganda ${ }^{39}$. Hal ini dilakukan untuk menekan adanya pemikiran ekstrimis yang masuk dariTimur Tengah. Apalagi, Tiongkok sudah sering terkena aksi teror. Maka daripada itu, pemerintah Tiongkok menekankan adanya ideologi komunis untuk masuk hingga ranah masyarakat Islam di Xinjiang. Di era Xi, pemerintah akanmengelaborasi Masjid dengan standar yang nasionalis. Misalnya, tata ruang yang ada di Masjid terdapat bahasa Mandarin atau bendera Tiongkok ${ }^{33}$. Contohnya adalah Masjid Huaisheng di Guangzhou ${ }^{40}$.

Seperti Muslim Uighur, Kristen di Tiongkok juga mengalamipembatasan. Peningkatan populasi dalam beberapa tahun belakang, membuat pemerintah Tiongkok memperkuat kebijakannya. 
Dilansir dari China Aid tahun 2020, pemerintah Tiongkok sudah menghilangkan kata "Christ" dan "Jesus" di dalam publikasi bahkan sosial media yang ada di Tiongkok dengan "JD" dan "YS"41. Penyingkatan kata tersebut merupakan salah satu peningkatan censorship. Selain bukan merupakan agama asli, pemerintah Tiongkok juga khawatir terkait dengan adanya gerakan anti- komunis yang sudah ada di negara lain dan akan ada di Tiongkok. Makadaripada itu, di era Xi, mencoba untuk mengintegrasi masyarakatnya dengan cara rumah ibadah. Misalnya di dalam Gereja akan disediakan dan ditata berupa arsitektur Tiongkok, nada harmoni Tiongkok, Gambar yang memiliki standar budaya Tiongkok, hingga kaligrafi. Seperti di Beijing, di tahun 2020, di depan Gereja St Joseph atau Gereja Katolik Wangfujing sudah ada bendera Tiongkok di depannya sebagai bentuk patuh terhadap partai dan negara.

Indoktrinasi tersebut juga masuk melalui aspek pendidikan dari sejak Sekolah Dasar (SD) hingga perguruan tinggi. Xi Jinping menargetkan elit-elit muda untuk patuh terhadap komunis. Menurut $\mathrm{Xi}$, pendidikan merupakan benteng dari ideologi yang harus dibentuk sejak dini ${ }^{42}$. Sejak tahun 2013 pemerintah Tiongkok telah melakukan perubahan struktural yang memungkinkan kontrol partai yang jauh lebih besar dan ketat sampai level perguruan tinggi, cabang partai juga dibentuk untuk memandu pekerjaan guru, peneliti dalam proyek-proyek tertentu. Para guru dan peneliti yang merangkap sebagai staf PKC, ditugaskan untuk melakukan propaganda komunis yang sudah dimandatkan oleh pemerintah ${ }^{42}$.

Xi Jinping juga memerintahkan agar cabang partai ini untuk tegas mencegah dan melawan semua jenis kegiatan misionaris dan penyusupan ilegal hal ini mengacu pada orang-orang yang berbeda pandangan politik. Ada tujuh topik tabu yang dilarang untuk didiskusikan di depan publik yaitu, nilainilai universal hak asasi manusia dan pemerintahan konstitusional yang demokratis; mendiskusikan kebebasan pers, masyarakat sipil, hak warga negara, kesalahan sejarah atas apa yang telah dilakukan oleh Partai Komunis China (PKC), membicarakan elit keuangan dan politik, dan membicarakan independensi peradilan. Adanya larangan- larangan ini membuat ruang demokratis masyarakat Tiongkok semakin sempit (ibid).

Menurut Sulaiman Gu,Universitas Georgia menyatakan bahwa, doktrin PKC dilatarbelakangi oleh ketidakpercayaan Beijing terhadap apapun yang berkaitan dengan liberal ${ }^{43}$. Menurut $\mathrm{Xi}$ Jinping, Tiongkok harus bebas dari barat dan salah satu upaya yang dapat dilakukan adalah membuat seluruh masyarakat daratan China untuk satu pemikiran dan sejalan melalui propaganda PKC (ibid). Berkaca dari protes yang dilakukan oleh Hongkong yang membuat pemerintah kesulitan oleh karena itupropaganda ini harus dilakukan sejak dini agar tidak ada pembangkangan di masa yang akan datang.

Dilansir dari BBC Indonesiapada tahun 2017, Universitas Renmin di Beijing dan Universitas Tianjin mendirikan Pusat Studi Pemikiran Xi Jinping (Komunisme). Ditahun yang sama pada tahun 2017, Xi pernah berpidato yang memaparkan pandangannya untuk 30 tahun ke depan $^{22}$. Xi sangat memfokuskan pembahasannya dengan model sosialisme yang memberikan 'sebuah pilihan baru bagi negara dan bangsa lain yang ingin mempercepat pembangunan dengan memelihara kemandirian'. Slogan lengkap dari gagasannya adalah 'Pemikiran $\mathrm{Xi}$ Jinping tentang Sosialisme dengan Karakteristik Tiongkok untuk Era Baru' yang disingkat dengan Pemikiran $\mathrm{Xi}$ Jinping (Komunisme). Selama pandemi Covid-19, situasi dan kondisi di Tiongkok tidak lepas dari kontrol Partai Komunis China (PKC) ${ }^{44}$. Di bidang pendidikan, PKC juga totalitas mengerahkan pejabat lokal serta memobilisasi batalyon dan kader partai agar secara rutin memeriksa ruang kelas, menyebarkan aplikasi dan teknologilainnya untuk memantau siswa dan staf sekolah sehingga pergerakan 
dan aktivitas mereka dapat dikontrol.

\section{KESIMPULAN}

Model althusserian sudah selaras dengan kebijakan pemerintah Tiongkok dalam mengontrol masyarakatnya. Sejak merdeka dibawah Mao Zedong, Tiongkok langsung mengimplementasikan sistem komunisme. Di bawah naungan PKC, Mao menjalankan beberapa sistem integrasi masyarakat salah satunya revolusi budaya yang hadir pada tahun 1966-1976. Salah satu kebijakan yang dilakukan adalah memberlakukannya kepada masyarakat Tiongkok untuk memiliki buku merah milik Mao Zedong.

Di era $\mathrm{Xi}$, perkembangandalam indoktrinasi masyarakat berkembang. Melalui media, Xi mencoba untuk menerapkan beberapa kebijakan dengan mengontrol langsung media untuk pro terhadap PKC. Misalnya, Xinhua.news dan CGTN. Di aspek agama, Xi menerapkan sinisasi agama pada tahun 2015 yang digunakan untuk mengintegrasi kepercayaan Tiongkok dalam payung komunisme. Walaupun sudah ada pasal no.36 terkait kebebasan beragama, PKC tetap membuat sikap yang tegas agar masyarakat yang memiliki kepercayaan akan pro-PKC. Hal ini juga terjadi ketika Xi meminta untuk adanya artikulasi budaya Tiongkok di dalam atau di sekitar rumah ibadah. Terakhir, Xi juga menerapkan komunisme dalam ke dalam ranah pendidikan misalnya ke Universitas maupun Sekolah Dasar (SD).

\section{DAFTAR PUSTAKA}

1. The Economist. The Opium Warsstill shape China's view of theWest. The

Economist. 2017. Sumber:

https://www.economist.com./christ mas-specials/2017/12/19/the- opiumwars-still-shape-chinas- view-of-thewest

2. Dean A, Dean PA, Branigan PT. China's Great Famine: the true story. The Guardian. 2013 Jan 1.

3. History. Cultural Revolution. 2020. Sumber:

https://www.history.com/topics/chi na/cultural-revolution
4. Chitwood, M. China's Crackdownon Islam Brings Back Memories of 1975 Massacre. 2021. foreign policy. https://foreignpolicy.com/2021/04/ 11/shadian-muslims-massacreuyghur-islamophobia/

5. Cheng $M$, Duan $C$. The changing trends of internal migration and urbanization in China: new evidence from the seventh National Population Census. China Population and Development Studies. 2021 Oct 18:121.

6. Song, C. The Han - China's Majority Ethnic Group. ChinaHighlights. 2021. Sumber:

https://www.chinahighlights.com/tr avelguide/nationality/han.htm

7. South China Morning Post.. Avisual history of China's Communist Party. 2021. Sumber:

https://multimedia.scmp.com/infog raphics/news/china/article/313933 1/ccp100yearanniversary/index.ht $\mathrm{ml}$

8. Creswell JW, Poth CN. Qualitative inquiry and research design: Choosing among five approaches. Sage publications; 2016 Dec 19.

9. Chua WF. Theoreticalconstructions of and by the real. Accounting, Organizations and Society. 1986 Jan 1;11(6):583-98.

10. Ching-yao $Y$. The Bitter Struggle between the KMT and the CCP. Asian Survey. 1981 Jun 1;21(6):622-31.

11. History. Long March. 2018.

12. Schram SR. From the "Great Union of the Popular Masses" to the "Great Alliance". The China Quarterly. 1972 Jan;49:88-105.

13. Phillips T. The Cultural Revolution:All you need to know about China'spolitical convulsion. The Guardian. 2016 May $11 ; 11$.

14. Harmini S, Nusyirawan N. Konsep Revolusi Kebudayaan Menurut Mao Zedong. Jurnal Filsafat.2007;14(1).

15. Armandhanu, D. China AkuiKesalahan Revolusi Budaya yangDicetus Mao Zedong. cnnindonesia.com. 2016. Sumber:

https://www.cnnindonesia.com/inte rnasional/20160517131857-134131296/china-akui-kesalahanrevolusi-budaya-yang-dicetus-maozedong 
16. BBC. China's Class of 1977: I tookan exam that changed China. bbc.com. 2017. Sumber:

https://www.bbc.com/news/worldasia-china-42135342

17. Huang LJ. The role of religion in Communist Chinese society. Asian Survey. 1971 Jul 1;11(7):693-708.

18. Wicaksono M. Republik Rakyat ChinaDari Mao Zedong Sampai Xi Jinping. Elex Media Komputindo; 2017 Oct 16.

19. Huang Y. China and global health governance. Indiana University Research Center for Chinese Politics \& Business Working Paper. 2012 May 1(26).

20. Qingjun Z. Mao Zedong. Prospects. 1994 Mar 1;24(1-2):93-106.

21. Fuxing, L. Leafrog progress in China'sEducation.chinatoday.com.cn. 2019.

http://www.chinatoday.com.cn/cte nglish/2018/sl/201906/t20190619 800171107.html

22. BBC Indonesia. Universitas Cina dirikan pusat studi untuk Pemikiran Xi Jinping. 2017.

https://www.bbc.com/indonesia/du nia-41761543

23. Niu X. Mao Zedong and Deng Xiaoping: A comparison of educational thought. Comparative and International Education.1996;25(1).

24. Boyle J. 11 slogans that changed China. BBC News. 2013 Sep;26.

25. Goldman M. Religion in post-mao China. The Annals of the American Academy of Political and Social Science. 1986 Jan;483(1):146-56.

26. Su X. Revolution and reform: The role of ideology and hegemony in Chinese politics. Journal of Contemporary China. 2011 Mar 1;20(69):307-26.

27. Cook S. Beijing's Global Megaphone. Freedom House. 2020 Jan.

28. Li H. New trends in China's media control at home and public diplomacy abroad. China Currents.2019;18(1).

29. Scott, C. D., \& George, A. As China Promotes Authoritarian Model, the Resilience of Its DemocraticTargets is Key. 2020. Sumber: https://www.justsecurity.org/73925/aschina-promotes-authoritarian-

30. Blumenthal, D., \& Zhang, L. China's
Censorship, Propaganda \& Disinformation. (Jewish Policy Center). 2020. Sumber:

https://www.aei.org/articles/chinascensorship-propagandadisinformation/

31. BBC. 'Buku merah' Xi Jinpingaplikasi yang paling populer di Cina. 2019. Sumber:

https://www.bbc.com/indonesia/m ajalah-47249724

32. Basuki, N. Islam di China dulu dankini. Kompas. 2020.

33. Cook, S. The Battle for China's Spirit. 2017. Freedom House.

34. The Diplomat. The CCP's Plan to 'Sinicize' Religions. 2018. Sumber: https://thediplomat.com./2018/06/t heccps-plan-to-sinicize-religions/

35. Harvey, T. The Sinicization Of Religion In China. 2019. Sumber: https://lausanne.org/content/lga/20 1909/sinicization-religion-china

36. Eto, N. Why Does the Xi Jinping Administration Advocate the "Sinicization" of Religion?. 2018. Sumber: https://www.spf.org/spfchina-observer/en/documentdetail008.html

37. BBC Indonesia. Muslim Uighur di Cina: Persekusi melalui kamp 'pendidikan- kembali'. 2018. Sumber:

https://www.bbc.com/indonesia/du nia45835871

38. Human Rights Watch. China: Crimes Against Humanity in Xinjiang. 2021. Sumber:

https://www.hrw.org/news/2021/04/19/ china-crimes-against- humanityxiniiang

39. The Week. Inside China's 'reeducation' camps. 2019. Sumber: https://theweek.com/articles/87702 4/inside-chinas-reeducation- camps

40. China Highlights. Guangzhou Huaisheng Mosque. 2021. Sumber: https://www.chinahighlights.com/gu angzhou/attraction/guangzhouhuaisheng mosque.htm

41. VOA. China Is Stepping Up Its Control over Religion. 2020. Sumber: https://www.voanews.com/east- asiapacific/voa-news-china/china- 
stepping-its-control-over-religion

42. Chen, M. P.. China's Ruling Party

Takes More Direct Control ofColleges,

Universities. $2021 . \quad$ Sumber:

https://www.rfa.org/english/news/c

hina/ccp-

universities04302021083055.html

43. Zhao, H. China Pushes Xi Jinping

Thoughtas Part of College

Education. 2020. Sumber:

https://www.voanews.com/east- asia-

pacific/voa-news-china/china- pushes-

xi-jinping-thought-part- college-

education

44. Hernandez, J. C. How China

Brought Nearly 200 Million

Students Back to School. 2020.

Sumber:

https://www.nytimes.com/2020/09/

12/world/asia/china-schools-

reopening.html 